\title{
Understanding consumption patterns of the established and emerging South African black middle class
}

\author{
RONELLE BURGER, MEGAN LOUW, BRIGITTE BARBARA ISABEL DE OLIVEIRA
} PEGADO AND SERVAAS VAN DER BERG

\section{Stellenbosch Economic Working Papers: 14/14}

KEYWORDS: MIDDLE CLASS, SOUTH AFRICA, CONSPICUOUS CONSUMPTION

JEL: D31, D12, D11

\footnotetext{
RONELLE BURGER

DEPARTMENT OF

ECONOMICS

UNIVERSITY OF

STELLENBOSCH

PRIVATE BAG X1, 7602

MATIELAND,

SOUTH AFRICA

E-MAIL:
}

RBURGER@SUN.AC.ZA

$$
\begin{gathered}
\text { MEGAN LOUW } \\
\text { DEPARTMENT OF } \\
\text { ECONOMICS } \\
\text { UNIVERSITY OF } \\
\text { STELLENBOSCH } \\
\text { PRIVATE BAG X1, } 7602 \\
\text { MATIELAND, } \\
\text { SOUTH AFRICA } \\
\text { E-MAIL: }
\end{gathered}
$$
MEGANLOUW@GMAIL.COM

$$
\begin{gathered}
\text { BRIGITTE BARBARA } \\
\text { ISABEL DE OLIVEIRA } \\
\text { PEGADO } \\
\text { DEPARTMENT OF } \\
\text { ECONOMICS } \\
\text { UNIVERSITY OF } \\
\text { STELLENBOSCH } \\
\text { PRIVATE BAG X1,7602 } \\
\text { MATIELAND, } \\
\text { SOUTH AFRICA } \\
\text { E-MAIL: }
\end{gathered}
$$

GITTIPGD@GMAIL.COM
SERVAAS VAN DER BERG DEPARTMENT OF ECONOMICS UNIVERSITY OF STELLENBOSCH PRIVATE BAG X1, 7602 MATIELAND, SOUTH AFRICA E-MAIL: SVDB@SUN.AC.ZA




\title{
Understanding consumption patterns of the established and emerging South African black middle class
}

\author{
Ronelle Burger, Megan Louw, \\ Brigitte Barbara Isabel De Oliveira Pegado and Servaas van der Berg \\ Department of Economics, University of Stellenbosch
}

\begin{abstract}
Existing empirical research on consumption patterns of the South African black middle class leans either on the theory of conspicuous consumption or culture-specific utility functions. This paper departs from treatment of the black middle class as a homogenous group. By differentiating between a securely established group, with characteristics and consumption patterns similar to the white middle class, and an emerging group, often with weaker productive characteristics, it formally introduces economic vulnerability as a driver of consumption patterns. Households new to the middle class or uncertain of continued class membership are viewed as vulnerable. Consumption patterns of the emerging black middle class are observed to diverge substantially from the other groups, in terms of greater signalling of social status via visible consumption and preoccupation with reducing an historical asset deficit. We expect many of its members to join the established classes over time, converging to a new 'middle class mean'.
\end{abstract}

Keywords: middle class, South Africa, conspicuous consumption

JEL: D31, D12, D11

\section{Introduction}

Much has been said about the levels of income inequality in South Africa, which do indeed remain amongst the worst in the world. Thabo Mbeki, then deputy president, described it eloquently back in 1993 when he first referred to South Africa as a country of two nations, one wealthy and historically white, and the other completely excluded from the economic mainstream, impoverished and black (Mbeki 2008). After 20 years of democracy a large proportion of South African remains excluded from the labour market and the mainstream economy. South Africa's unemployment rate and Gini coefficient have remained stubbornly high. Increases in the frequency and violence of protest marches calling for improved service delivery and better economic conditions may be evidence that frustrations amongst the marginalised are escalating (Office of the President, 2013; Alexander, 2010).

The enduring problems with unemployment and the poor quality of service delivery sometimes mask the post-apartheid successes. This period has also seen a considerable expansion in service delivery coverage and a rapid increase in black affluence. In an article in this edition, Visagie (2014) shows that an additional 3.1 million black people were added to the middle class between 1993 and 2008. This shift is significant not only for markets and for economic growth, but in a broader societal context it can be interpreted as an indication that South African society has become more open and dynamic. Furthermore, a growing middle class is considered socially beneficial by Easterly (2001) and 
others due to its association with desirable outcomes such as more prudent policy, more education and improved political stability and democracy.

This paper attempts to contribute to a better understanding of the position and the impact of the rising black middle class on the South African economy by investigating the consumption preferences and choices of this growing consumer group. What requires explanation is why consumer patterns of the black middle class differ from those of their white peers. Following Bourdieu's view (1984) that dominant tastes are a reflection of social power of different classes as reflected in their cultural capital, one would expect a convergence in the patterns of consumption of individuals entering the middle class to that of the dominant white middle class.

Much of the initial research on the purchasing decisions of black middle class group were conducted by consumer market researchers eager to define and describe such spending habits in terms of new consumer categories and emphasising differences in underlying utility functions ('tastes') between race groups that they often appear to regard as immutable. However, the consumer market focus on preferences and tastes has been criticised for perpetuating narrow stereotypes of the black middle class as conspicuous consumers with a taste for expensive cars, designer labels and large houses and a reputation as poor creditors. There have been only a handful of studies looking for more fundamental explanations for differences in spending patterns of the emerging black middle class in South Africa, notably Nieftagodien and Van der Berg (2007) and Kaus et al (2010).

The aim of this paper is to provide more encompassing hypotheses for why more vulnerable members of the middle class may exhibit different spending priorities. Significantly, these rival explanations find the rationale for the differential spending patterns of the emerging middle class in their vulnerable circumstances and their asset deficit, rather than unique intrinsic preferences. Such a conceptual shift may be subtle, but has important implications for anticipated trends. If differential spending patterns are attributable to intrinsic differences, then such gaps will remain, whereas if they are due to the vulnerable new entrant position of the emerging black middle class, then such gaps will fade and dissipate over time.

A first applicable theory relates to conspicuous consumption, as put forward by Veblen late in the $19^{\text {th }}$ century. Under this theory, individuals derive utility from the social status linked to visible consumption of certain goods. Thus conspicuous consumption is consumption that is intended to be visible. This is in effect signalling wealth, which is generally unobserved. It is relative in the sense that an individual's status is socially contingent, i.e. relative to that of other individuals within the reference group. In South Africa, race can be used to define the reference group, since race has played a significant role in forming cultural and economic identities. Kaus (2010) finds variance in conspicuous consumption amongst groups, specifically 35-50 percent greater expenditure on visible consumption amongst coloured and black households relative to whites, linking this to a signalling model of social status. A second applicable theory is that expenditure patterns within less affluent groups are driven by historical asset deficits. Black, coloured and Indian households are playing 'catch up' with the household asset levels typical of more established white middle class households.

This paper builds on previous studies demonstrating an economic perspective to show that expenditure patterns are primarily driven by rational and dynamic socioeconomic factors that need not resort to explaining differences in underlying utility functions (tastes) or any other deterministic racial grouping attributes. These include status seeking in a broader sense as well as reducing the 
asset deficit. Together, these factors explain a significant portion of the observed variation in consumption expenditure across black and white members of the middle class.

Following a literature review, definitional issues are discussed and the methodology applied in this paper is presented. Results of descriptive analysis and modelling on the Income and Expenditure Survey of 2010/11 suggest that greater conspicuous consumption observed amongst the black group reduces when taking into account new membership or uncertainty regarding future membership of the middle class. As the emerging black middle class establishes itself and members continue to transition into the established group, it is likely that substantial convergence to a new South African 'middle class mean' will take place.

\section{Understanding the term "conspicuous consumption"}

Much of the initial work on the emerging black middle class viewed this group primarily as an attractive consumer market, depicting its members as highly ambitious and aspirational in their spending patterns. The foundations for this belief are found in the group's investment in education, its robust expenditure underpinned by the recent growth in credit extension, and rising incomes associated with black economic empowerment policy, upward social mobility and economic growth. Krige (2011 \& 2009) notes that commentators and researchers have criticised the work on so-called 'black diamonds' as propagating cultural stereotypes. Members of the black middle class argue that the black middle class is incorrectly painted as greedy and consumerist, resulting in what is seen as a simplistic, patronising and inaccurate representation of reality. Such a stylised caricature of black middle class consumer suggests instead that membership of a specific subgroup is the most important explanation for observed consumer patterns, obscuring the role of rational economic drivers of consumption expenditure.

Veblen's economic theory of conspicuous consumption proposes that individuals gain social status by signalling their wealth to their reference by engaging in conspicuous leisure or conspicuous consumption, the latter defined as visible consumption of certain goods which are associated with social status (Kaus 2010, Trigg 2001). Veblen (1899) argued individuals demonstrate their wealth and so gain in social status by showing that they can afford to waste time, effort and money. Veblen however also noted that amongst the more established members of the upper class the need to signal wealth may be diminished - partly because they can signal their wealth through a set of distinct habits and tastes which they acquired tacitly through their social upbringing.

This insight is central to the more recent work of Bourdieu (1984) on how tastes and preferences can signal and entrench class. He argues that taste and preferences are class markers that distinguish and legitimise privilege. Each class therefore aspires to mimic the tastes and consumption patterns of those above it. According to such a perspective the established upper classes would be less likely to exhibit conspicuous consumption while it would be important for the middle class to distinguish themselves from the working class (Trigg, 2001).

Bourdieu believes that conspicuous consumption need not be crude and deliberate ('showing off'), but can often work through an unconscious code acquired through socialisation and motivated by the habitus - Bourdieu's conceptualisation of the complex and changing social constellation which implicitly and tacitly governs and guides the choices of the members of social groups (Lamont and Lareau, 1988). Add to this the distinction and trade-off between cultural and economic capital and it becomes clear that Bourdieu's theory allows for a more complicated, but also more fluid and 
dynamic, class structure. It should be borne in mind that this paper does not make any normative judgments on taste, or indeed even attempt to measure what constitutes 'good taste' in the context of South African society. Instead, it defines conspicuous consumption as expenditure on categories of goods and services which may be considered as luxury items associated with affluent lifestyles.

\section{Background: Empirical investigations of consumption and class}

The work of Veblen and more recently Bourdieu have inspired a large body of empirical work examining the relationship between conspicuous consumption and class. Charles et al (2009) and Kaus (2010) postulate that conspicuous consumption is socially contingent in the sense that an individual's visible expenditure is influenced by the characteristics of the reference group and his/her position within the income distribution of this reference group (Charles et al 2009).

In their work they examine whether conspicuous consumption will increase as mean income of the reference group decreases. The intuition is that ann individual from a relatively poor reference group who aspires to achieve social status of higher groups will have an incentive to engage in additional signalling, given the general perception of low status associated with this group.

They also investigate whether conspicuous consumption will increase as income inequality within the reference group increases. The intuition here is that additional signalling may be required to demonstrate positioning near the top of the reference group income distribution. Lastly, they explore whether conspicuous consumption will increase with the permanent income of the relevant household.

Charles et al (2009) search for interracial evidence of conspicuous consumption in USA data, using both the Consumer Expenditure Survey from 1986-2002 and other nationally representative household surveys and panels. Defining conspicuous consumption as expenditure on items such as cars, clothing and jewellery, they find that black and Hispanic individuals devote substantially larger shares to such conspicuous consumption, consistent with a model of status seeking. The trade-off for higher visible consumption is lower consumption of all other categories of current consumption notably education and health - as well as future consumption. This implies a significant and intertemporal cost to conspicuous consumption in terms of other consumption forgone.

The authors also examine conspicuous consumption within reference (race and regional) groups. They find that visible consumption increases with income and the dispersion (inequality) of reference group income, while decreasing with reference group income (Charles et al 2009). Since a socially contingent model of conspicuous consumption explains much of the observed variation in conspicuous consumption, the authors therefore do not give much weight to deterministic factors such as racial differences in tastes.

Kaus (2010) follows a similar methodology but focuses instead on South Africa using the Income and Expenditure Surveys of 1995, 2000 and 2005. He finds that coloured and black households spend 35 $50 \%$ more on visible goods than do comparable white households ${ }^{1}$. When exploring the status seeking model as an explanation for this consumption, Kaus also finds that visible consumption is higher when reference group income is lower (all groups). However, the results are not replicated within all race groups, and he therefore does not rule out that there are differences in underlying

\footnotetext{
${ }^{1}$ However, note that this effect is not observed for cars in the South African context (Kaus 2010: 20).
} 
tastes (utility functions). Trade-offs ocur through lower spending on health, housing, entertainment and communications amongst black and coloured households.

Whilst these studies link conspicuous consumptions to specific characteristics within reference groups, they do not take into account the potential impacts of small movements across a class threshold on expenditure patterns. Since income-based approaches to the middle class assume enjoyment of an aspirational lifestyle associated with incomes above a certain threshold, proximity to this point should be an important driver of expenditure patterns within the middle class. An innovative new study by Lopez-Calva and Ortiz-Juarez (2013) examines vulnerability to poverty in the context of a rising middle class in Central and Latin America, observing that a group of households located between the middle class and the poor in the income distribution remains vulnerable to falling back into poverty. This may be explained in terms of structural characteristics of these households, applying the Weberian view of class, which groups individuals into classes according to common economic 'life chances' which influence their market income opportunities. The middle class is defined as a group benefiting from a broad skills base and substantial investment in education, offering it a significant chance of attaining economic prosperity over time. .

The income-based approach to definitions of the middle class necessarily segments the population independently of productive characteristics such as educational attainment. Accordingly, there may be 'sub groups' within the affluence-based middle class group which exhibit fundamentally different characteristics associated with social mobility, thus enjoying very different 'life chances'. In a similar vein, Goldthorpe and McKnight (2004) distinguish between groups of workers on the basis of economic security, stability and prospects (Lopez-Calva and Ortiz-Juarez 2013). This echoes Ravallion's work (2009) which points out that the growing middle class in developing countries remains vulnerable, despite its newly acquired relative affluence. This vulnerability itself may be an important driver of expenditure patterns, should a household feel insecure due to recently joining the middle class or lacking sufficient characteristics to be confident of sustaining class membership.

A separate explanation for differing racially based expenditure patterns is advanced by Nieftagodien and Van der Berg (2007), framing the issue in terms of an 'asset deficit'. They argue that the ramifications of past economic racial segregation could explain currently observed differences in asset levels, with black and coloured households consequently at a disadvantage in terms of ownership of household assets. Their research shows that black middle class households have asset deficits and are more likely than their white counterparts to purchase assets.

\section{Data}

This paper mainly uses the Income and Expenditure Survey 2010/2011 for this analysis. The Income and Expenditure Survey (IES) was conducted by Statistics South Africa (Stats SA) during the period of September 2010 and August 2011. Data were recorded for 25328 households across the country over a 12 month period. The IES is mainly conducted to provide relevant statistical information on household consumption expenditure patterns for the calculation of the weights for the Consumer Price Index. A combination of diary and recall methods was used to sample these households. Each household was presented with a questionnaire and a two-week diary. The diary acquisition approach may generate underlying measurement error due to the fact that respondents may become fatigued or forget to complete their diaries on a daily basis - thus they may not comprehensively record all actual expenditures over the two week period (Visagie \& Posel 2013). 
Though the primary aim of the IES is to provide information for the readjustment of the consumer price index basket of goods and service, a secondary aim is to provide additional information on socio-economic conditions, such as to infer inequality measures. In this paper, additional information on the presence of assets is also used to create two indices to rank middle class households in the context of socio-economic conditions.

\section{Analysis}

Following previous work in this field, the analysis uses an income-based definition of the middle class. While there are a range of alternative approaches to defining the middle class (see Burger et al in this edition for a more thorough discussion), the aim is to examine what consumption patterns reveal about the evolving social landscape and de-racialisation in post-apartheid South Africa. Only a lower income cut-off is applied, set at a level which yields a middle class comprising the most affluent 15 per cent of the population, namely R53 217 per capita per annum in 2010/11 terms. An upper income cut-off is not applied, because such an incision leaves only a slither of very rich at the top. Additionally, because of the small number of observations in what would be the upper-income group within the black population, it is difficult to meaningfully analyse such a category over time or to decompose it by other attributes and qualities. While the distinction between the middle and upper class may be of interest for understanding capital formation or the distributional effects of growth, the wealth of the upper classes cannot be captured and represented reliably and accurately without specialised wealth surveys. This analysis thus investigates the distinct consumption patterns of households enjoying at least middle class lifestyles, namely those with sufficient income to make allocations towards discretionary expenditure.

The black middle class is further segmented into two groups for the current analysis: emerging and established, defined through scoring on an asset index. These groups are roughly equal in size; further detail on their characteristics is provided later. Of the three most common methods used to construct an asset index, namely factor analysis (FA), principal component analysis (PCA) and multiple correspondence analysis (MCA), MCA is selected as it imposes fewer restrictions on the survey matrix (it does not, for instance, assume a normal distribution of the underlying variables) and can use categorical variables and is thus the superior method in the context of the IES 2010/11 data (Booysen, Van der Berg, Burger, Maltitz \& Du Rand 2008). Using MCA as a data reduction technique, an asset index is constructed and black households within the middle class as defined here are then divided on the basis of this index into those with more assets (constituting a more established grouping within the middle class), and those with fewer assets, referred to as an emerging middle class.

The foundation for applying this categorisation is found in earlier work which suggests that a high expenditure priority for new members to the middle class is the acquisition of assets typically associated with middle class lifestyles, such as white goods and cars (Nieftagodien and Van der Berg, 2007). By this rationale, established households which have a longer membership of the middle class have accumulated many of the goods traditionally found in white middle class households, and should thus score higher on the asset index. A particular benefit of applying this categorisation is that per capita household expenditure can be used to instrument for permanent income in regression analysis, aligning with Veblen's theoretical foundations. 
To illustrate both the asset deficit and the purchasing of assets by black households, it is useful to turn to data from the 2012A version of the All Media and Products Survey (AMPS) on ownership and purchases of large household appliances. This survey shows that white households with a monthly income of R8 000 or more are six times more likely than their black counterparts to own a tumble dryer, whereas black households in this subsample are five times more likely to have recently acquired a tumble dryer. For this household income group, black households are only half as likely as white households to own a washing machine, yet responses regarding purchasing patterns indicate that they appear four times more likely to have recently bought a washing machine. Similarly, there is also evidence that black households in this group are significantly more likely to purchase microwaves and refrigerators. This provides some evidence that black households in this group experience an asset deficit compared to whites of similar income, but they are allocating more of their resources to eliminating this deficit.

The purpose of distinguishing between emerging and established black middle class groups is to allow for a more nuanced, dynamic analysis of spending patterns which implicitly takes into account the duration and degree of class inclusion. In describing the middle class in 2005, Schlemmer (2005: 5) refers to lagging security with respect to asset ownership, status and self-confidence within the group, still very new and small then ${ }^{2}$. It is a hypothesis of the current analysis that such insecurity remains a characteristic feature of the emerging component of the black middle class, associated with households that have recently joined the middle class or whose grasp on middle class status is tenuous, for example due to unstable forms of income. This builds on the approach taken by Schlemmer, which refers to a 'core middle class' comprising households containing highly skilled workers such as professionals and managers, as distinct from a 'lower middle class' made up of more modestly salaried clerical workers, teachers, nurses and so on. Specifically he observed a notable lack of unity in class identity in this group.

The analysis applies an augmented version of the permanent income hypothesis to model spending patterns. $^{3}$

Dummy variables indicate whether the head of a household is black, Indian or coloured (the reference group is white household heads). Other standard controls that may proxy for differences in prices, tastes and preferences include a dummy variable for rural location, the number of children in the household, the number of elderly people in the household and a dummy indicating whether the head of the household is female. Per capita household expenditure is included as an indicator of the household's spending power (for developing countries, expenditure is regarded as a more reliable and accurate measure of well-being that can also proxy for income).

In line with the theories of Modigliani \& Brumberg (1954) and Milton Friedman (1957), income smoothing could play an important role in consumption patterns. The age and the years of education of the household head influence their earning capacity, i.e. they act as further proxies for permanent income (Charles et al 2009: 432). Intuitively, one would expect that a household with a higher

\footnotetext{
${ }^{2}$ Almost a third of black middle class survey respondents identified themselves as 'working class' (Schlemmer 2005).

${ }^{3}$ Formally, we model conspicuous consumption expenditure share $=\beta_{0}+\beta_{1}{ }^{*} r_{i}+\varphi{ }^{*} p_{i}+b * a+\theta X_{i}+\eta_{i}$, where ' $r$ ' is a range of racial dummy variables; ' $p$ ' represents the household's permanent income, instrumented here by per capita household income; ' $a$ ' represents the score on the asset index; and Xi is a vector of controls.
} 
expectation of future earnings may consume more than other households earning the same income currently.

Modelling the share of expenditure devoted to conspicuous consumption as the dependent variable should control for asset ownership, which is expected to vary between groups. According to the asset deficit hypothesis, the observed racial differences in consumption expenditure patterns between groups are expected to decrease substantially over time because they are dictated by asset accumulation patterns - over lifecycles, but also across generations. Most members of the black middle class are young and in many cases they are the first generation of their families to belong to the middle class. Compared to both their older counterparts and those born into middle class families (e.g. many whites members of the middle class), these younger middle class households start their careers with a deficit of assets. Within their financial constraints, such households can only eliminate their asset deficit gradually and over an extended period.

The asset index is estimated using multiple correspondence analysis on binary variables reflecting ownership of a list of white goods and other household assets, including televisions, DVD players, refrigerators, stoves, microwaves, washing machines, motor vehicles, computers, cameras, telephones, satellite dishes, internet, furniture and ownership of a brick house. Finally, control variables comprise dummy variables for rural location and female household headship, as well as number of children and older members (adults aged 60 or older) within the household.

Firstly, descriptive analysis is presented in Table 1, reflecting some interesting contrasts between the subgroups comprising the middle class.

As expected, black established and white middle class groups look quite similar in terms of productive characteristics. Approximately half of households in these groups have at least a diploma, while more than 20 percent have a degree. Similarly, household heads are older and probably well established in their careers, reflected in high scores on the asset index. The most obvious difference is the much higher per capita income level of white household heads, perhaps due to a combination of more experience (household heads are older), greater historical representation in financially rewarding occupations and more reliance on passive income streams. This last factor is borne out by the much lower employment rates of white household heads, which is not fully explained by slightly higher self-employment rates.

By contrast, emerging black middle class households as a group display substantially less entrenched prosperity. Household heads are younger and thus less experienced, and much less likely to have tertiary education than their peers. Furthermore, emerging black households are more likely to be female headed, single person households, and located in rural areas. In the South African context, all of these characteristics are typically associated with lower incomes and greater vulnerability. It is thus unsurprising that scores on the asset index are much lower, in line with relatively low per capita incomes.

It seems quite likely that a portion of the black emerging group - typically with young, well-educated household heads - will transition into the black established group over time, as they gain experience in the workplace and are promoted into more lucrative positions. However, a significant portion of this group is structurally less advantaged and will thus remain marginal members of the middle class 
group, their social mobility potential capped by lack of access to opportunities in urban labour markets, or by not having spouses earning income, for example.

Table 1: Descriptive characteristics of the middle class

\begin{tabular}{|c|c|c|c|c|}
\hline & Middle class & $\begin{array}{l}\text { Black emerging } \\
\text { middle class }\end{array}$ & $\begin{array}{l}\text { Black established } \\
\text { middle class }\end{array}$ & $\begin{array}{l}\text { White } \\
\text { middle class }\end{array}$ \\
\hline $\begin{array}{l}\text { Total population (total SA } \\
\text { population }=50375543 \text { ) }\end{array}$ & 7553951 & 1496533 & 1293608 & 3438123 \\
\hline$\%$ of SA population & $15.00 \%$ & $2.97 \%$ & $2.57 \%$ & $6.82 \%$ \\
\hline $\begin{array}{l}\text { Household head has at least } \\
\text { degree }\end{array}$ & $19.48 \%$ & $9.09 \%$ & $27.77 \%$ & $22.52 \%$ \\
\hline $\begin{array}{l}\text { Household head has at least } \\
\text { diploma }\end{array}$ & $43.29 \%$ & $28.45 \%$ & $56.49 \%$ & $48.57 \%$ \\
\hline $\begin{array}{l}\text { Education of household head } \\
\text { (years) }\end{array}$ & 11.88 & 10.71 & 12.48 & 12.34 \\
\hline Age of household head & 47.0 & 42.3 & 45.2 & 49.9 \\
\hline$\%$ households with female head & $18.95 \%$ & $28.61 \%$ & $21.12 \%$ & $15.38 \%$ \\
\hline \% household heads employed & $80.9 \%$ & $88.7 \%$ & $84.6 \%$ & $73.8 \%$ \\
\hline$\%$ household heads self-employed & $9.4 \%$ & $7.5 \%$ & $7.6 \%$ & $11.9 \%$ \\
\hline$\%$ rural & $8.0 \%$ & $20.1 \%$ & $9.1 \%$ & $5.2 \%$ \\
\hline Average household size & 3.55 & 3.02 & 4.19 & 3.38 \\
\hline$\%$ of households single members & $8.8 \%$ & $24.5 \%$ & $2.7 \%$ & $6.2 \%$ \\
\hline Average per capita income & R 138673 & R 97036 & R 120603 & R 171203 \\
\hline Average per capita expenditure & R 96268 & R 47331 & R 81880 & R 131372 \\
\hline Average conspicuous consumption & R 16924 & R 10830 & R 20673 & R 18034 \\
\hline $\begin{array}{l}\text { Mean value of asset index } \\
\text { (mean }=0 \text {, std dev }=1 \text { ) }\end{array}$ & 0.210 & -0.993 & 0.472 & 0.562 \\
\hline $\begin{array}{l}\text { Conspicuous consumption } \\
\text { including new car purchases }\end{array}$ & R 31483 & R 16001 & R 39318 & R 34508 \\
\hline $\begin{array}{l}\text { Conspicuous consumption share } \\
\text { (average across households) }\end{array}$ & $6.95 \%$ & $10.67 \%$ & $7.79 \%$ & $4.99 \%$ \\
\hline
\end{tabular}

Source: Own calculations from IES2010/11

Interestingly, and in line with the hypothesis, the black emerging group allocates more expenditure towards both conspicuous consumption items and assets than either of the other subgroups.

Regression analysis sheds further light on this question, by controlling for factors which may be responsible for variation. 
Table 2: Regression analysis of conspicuous consumption

\begin{tabular}{|c|c|c|c|c|}
\hline VARIABLES & (1) & $(2)$ & (3) & $(4)$ \\
\hline \multirow[t]{2}{*}{ Log expenditure per capita } & -0.01523 & -0.00891 & $-0.03201 * *$ & -0.02549 \\
\hline & $(0.01546)$ & $(0.01560)$ & $(0.01600)$ & $(0.01615)$ \\
\hline \multirow[t]{2}{*}{ Log expenditure per capita squared } & -0.00005 & -0.00033 & 0.00090 & 0.00061 \\
\hline & $(0.00088)$ & $(0.00088)$ & $(0.00091)$ & $(0.00091)$ \\
\hline \multirow[t]{2}{*}{ Age of household head } & $-0.00096 * * *$ & $-0.00093 * * *$ & $-0.00099 * * *$ & $-0.00095^{* * *}$ \\
\hline & $(0.00009)$ & $(0.00009)$ & $(0.00009)$ & $(0.00009)$ \\
\hline \multirow[t]{2}{*}{ Rural } & $-0.00652 * *$ & $-0.00744 * *$ & $-0.00551 *$ & $-0.00633^{*}$ \\
\hline & $(0.00325)$ & $(0.00326)$ & $(0.00329)$ & $(0.00330)$ \\
\hline \multirow[t]{2}{*}{ Number of children in household } & $-0.00615^{* * *}$ & $-0.00507 * * *$ & $-0.00613^{* * *}$ & $-0.00510^{* * *}$ \\
\hline & (0.00119) & $(0.00125)$ & $(0.00121)$ & $(0.00126)$ \\
\hline \multirow[t]{2}{*}{ Number of elderly people in household } & -0.00337 & -0.00346 & -0.00315 & -0.00329 \\
\hline & $(0.00214)$ & $(0.00214)$ & $(0.00215)$ & $(0.00215)$ \\
\hline \multirow[t]{2}{*}{ Female-headed household } & 0.00315 & 0.00347 & 0.00309 & 0.00343 \\
\hline & $(0.00215)$ & $(0.00215)$ & $(0.00215)$ & $(0.00215)$ \\
\hline \multirow[t]{2}{*}{ Coloured } & $0.01335^{* * *}$ & $0.01293^{* * *}$ & $0.01346 * * *$ & $0.01312 * * *$ \\
\hline & $(0.00350)$ & $(0.00350)$ & $(0.00351)$ & $(0.00351)$ \\
\hline \multirow[t]{2}{*}{ Indian } & $-0.00932 * *$ & $-0.00929 * *$ & $-0.00936 * *$ & $-0.00929 * *$ \\
\hline & $(0.00416)$ & $(0.00416)$ & $(0.00415)$ & $(0.00415)$ \\
\hline \multirow[t]{2}{*}{ Emerging black middle class } & $0.03358 * * *$ & $0.02835^{* * *}$ & $0.03323 * * *$ & $0.02800 * * *$ \\
\hline & $(0.00287)$ & $(0.00341)$ & $(0.00289)$ & $(0.00342)$ \\
\hline \multirow[t]{2}{*}{ Established black middle class } & $0.01526 * * *$ & $0.01540 * * *$ & $0.01504 * * *$ & $0.01509 * * *$ \\
\hline & $(0.00300)$ & $(0.00299)$ & $(0.00301)$ & $(0.00301)$ \\
\hline \multirow[t]{2}{*}{ Asset index } & & $-0.00437 * * *$ & & $-0.00447^{* * *}$ \\
\hline & & $(0.00153)$ & & $(0.00156)$ \\
\hline \multirow[t]{2}{*}{ Education attainment of household head } & & & -0.00048 & -0.00030 \\
\hline & & & $(0.00039)$ & $(0.00040)$ \\
\hline \multirow[t]{2}{*}{ Constant } & $0.24592 * * *$ & $0.21110^{* * *}$ & $0.32595^{* * *}$ & $0.28857^{* * *}$ \\
\hline & $(0.06851)$ & $(0.06953)$ & $(0.07104)$ & $(0.07218)$ \\
\hline Observations & 4,392 & 4,392 & 4,324 & 4,324 \\
\hline R-squared & 0.21419 & 0.21565 & 0.22115 & 0.22262 \\
\hline
\end{tabular}

Standard errors in parentheses

$* * * \mathrm{p}<0.01, * * \mathrm{p}<0.05, * \mathrm{p}<0.1$

Source: Own calculations from IES2010/11

Conspicuous consumption will by its very nature be defined to include different expenditure categories, being a socially contingent concept. In our paper focusing on South African consumers, both Veblen's theoretical framework for conspicuous consumption and the practical constraints arising from survey data quality and accuracy informed its measure. Conspicuous consumption was accordingly defined to include expenditure associated with clothing, footwear, restaurants, grooming products and services, watches, handbags, televisions and satellite dishes. ${ }^{4}$ However,

\footnotetext{
${ }^{4}$ One may argue that purchasing a car is a necessity in a country such as South Africa which historically has offered individuals limited options for reliable and convenient public transport, particularly within urban areas. Therefore, only excessive expenditure on (luxury) cars can be regarded as conspicuous consumption. Given limited information on the nature and value of car purchases in the data and the fact that the large value of
} 
when interpreting this it is important to bear in mind that even the poorest households will allocate some money towards footwear, clothing and grooming. Only that part of expenditure on these items that exceeds functional levels can properly be regarded an attempt to signal wealth. Therefore, this variable should be interpreted in a relative sense. Some of what is interpreted as conspicuous consumption could be necessary and functional investment in household assets and other goods.

The relationship between logged household per capita expenditure and conspicuous consumption as a share of expenditure is an inverted $U$, rising steeply at low levels of expenditure and then flattening out and eventually declining at higher levels of expenditure.

Table 2 above shows the factors associated with a higher conspicuous consumption share for middle class South Africans. Because of the correlation between household expenditure per capita and the educational attainment of the head of the household, four sets of results are presented, with educational attainment and also the asset index not appearing in all regressions. Each regression shows a basic model of spending, including proxies for spending power (i.e. expenditure per capita and its square) and a range of demographic characteristics that can drive consumption priorities and preferences (i.e. race and household structure). A dummy for a rural location is included because rural inhabitants often face different prices and choice sets than urban inhabitants. Charles et al (2009) and Kaus (2010) define reference groups as a composite of race group and region; since sufficiently comprehensive district level data do not exist in the IES, the regressions simply control for the urban/rural distinction.

All the coefficients have the expected signs. Expenditure per capita and expenditure per capita square both have negative coefficients, showing that for the South African middle class the share of expenditure allocated to conspicuous consumption decreases with an increase in expenditure per capita. As reported earlier, this negative relationship only holds at the top end of the expenditure distribution and there is a positive relationship between conspicuous consumption share and expenditure at lower levels of expenditure.

Age has a negative coefficient, showing that younger members of the middle class tend to allocate a greater share of expenditure towards conspicuous consumption. Given that separate proxies for expenditure, education and assets have been included, the negative coefficient on age may be interpreted as a possible indication that younger members of the middle class may still feel more vulnerable, perhaps because they have fewer years of experience in the labour market. This may lead to them being more easily elicited to signal their wealth through their consumption behaviour.

Rural inhabitants tend to have a lower conspicuous consumption share, which could perhaps be attributable to lower social pressure in rural areas, i.e. the reference group may differ.

As would be expected, households with more dependents (children and elders) are less prone to conspicuous consumption. Put differently, where a greater share of the household consists of adults

car purchases would result in it dominating conspicuous consumption spending patterns, car spending was not included in our analysis. This decision deviates from the work of Charles et al (2009) and Kaus (2010), who included expenditure on cars as conspicuous consumption in the American and South African contexts respectively. 
of working age, a higher conspicuous consumption share would be expected. This would also be associated with higher disposable income in households with more productive capacity.

The coefficient on female-headed households is positive, but not significant. A positive association was expected due such households representing a highly vulnerable segment of the population.

The white middle class is the reference group, accordingly a positive coefficient on the racial indicator variable shows that members of this racial group tend to devote a higher proportion of expenditure to conspicuous consumption than the white middle class. The work of Charles et al (2009) and Kaus (2010) would predict that the urge to signal wealth would be stronger amongst coloured and black South Africans, who experience higher intra-group inequality and lower mean income. Consequently high earning members of these groups would be more inclined to use visual cues to set themselves apart from the rest of their reference groups. These results confirm this and show that, all other things equal, coloured and black households spend a significantly larger share of their money on items that can visibly signal wealth.

Note, however, that the coefficient on the black emerging middle class indicator variable is almost double that of the coefficient on the black established middle class. This suggests that a large part of observed black conspicuous consumption is driven by the emerging middle class group, which appears to have a greater signalling need even after controlling for income levels. This may be associated with recent arrival in or due to uncertain continued membership of this status class, due for instance to relatively low educational attainment.

In line with the asset deficit hypothesis, the asset index is significant and negative and reduces the coefficient on the black emerging indicator variable. This shows that even after almost two decades of democracy, a significant proportion of what is classified as conspicuous consumption is fuelled by attempts to close the asset gap. Interestingly, the figure below shows that the black middle class' conspicuous consumption shares converge towards white middle class levels as their asset levels increase. The wide divergence in conspicuous expenditure at low levels of assets may suggest that for first generation middle class members the asset accumulation process may run parallel to and proxy for equally important socio-economic orientation and consolidation processes that may include the expansion and deepening of social networks, gaining more labour market experience and tacit knowledge about social conventions and systems. Such anchoring and rooting processes would enhance feelings of security and belonging and reduce vulnerability, which could then reduce the need to signal wealth via conspicuous consumption. 
Figure 1: Conspicuous consumption shares of black and white middle class

\section{households by asset index}

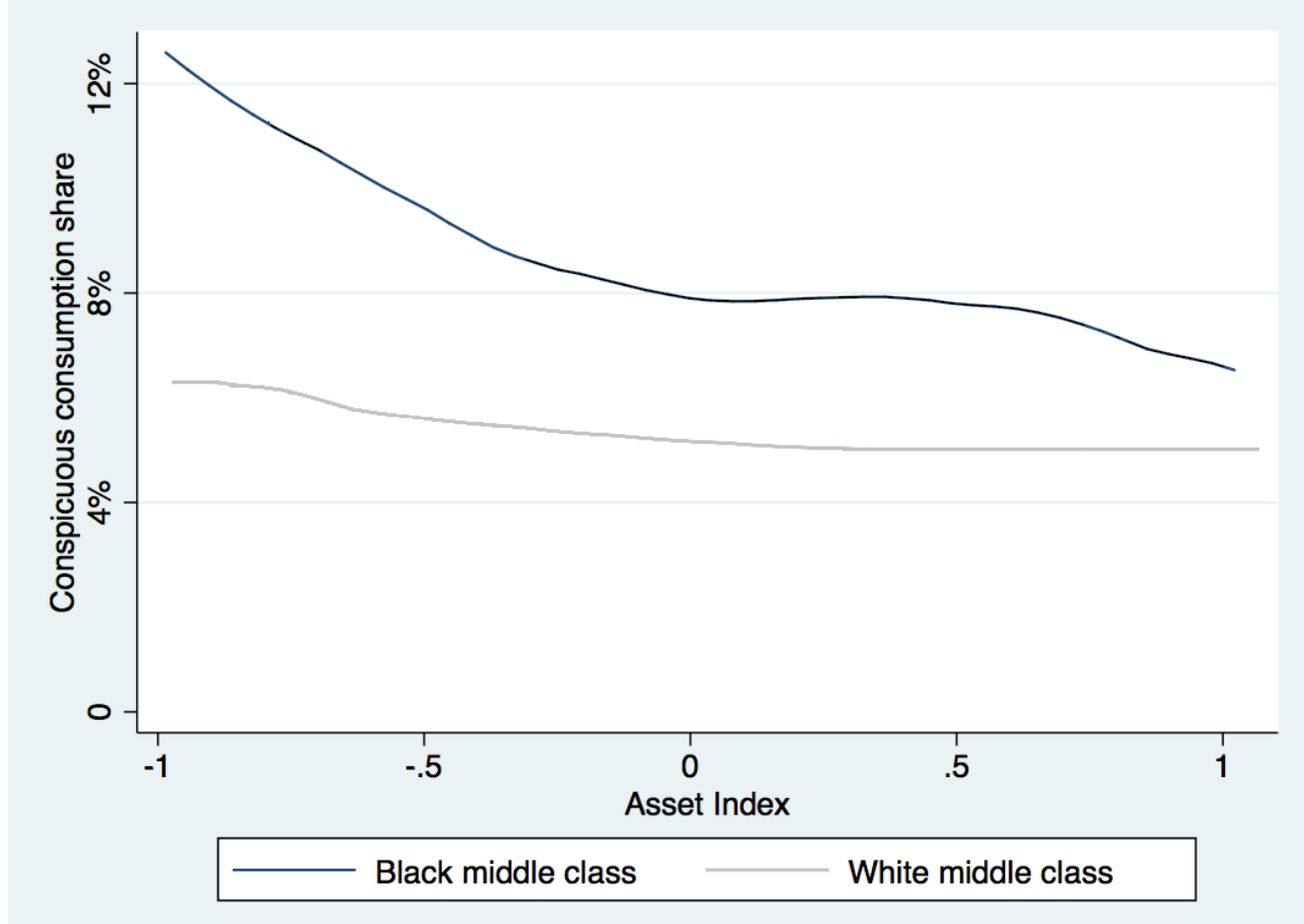

Source: Own calculations from IES2010/11

Whilst black middle class households spend more on conspicuous consumption as a share of total expenditure, it is equally true that their spending patterns also reflect that they are still catching up on household asset stocks. This is particularly true for the emerging group amongst black middle class households. In other words, there does not appear to be a significant trade-off for these households between conspicuous consumption expenditure and filling the asset deficit. To augment regression analysis, Figure 2 below shows that middle class households with lower stores of assets (i.e. emerging middle class) were more likely to report recent asset purchases (over the previous 12 months) than their established counterparts. The only exceptions are cars and TVs. Regarding assets such as these where major innovations occur frequently, consumers may replace goods earlier than strictly required in order to signal social status or to access productivity gains or luxury features associated with the additional functionality of the new version. For most assets, though, the emerging black middle class is considerably more likely to have reported recent purchases. The strikingly high incidence of computer purchases amongst the emerging black middle class group is particularly interesting as it may speak to the socialisation associated with recently joining the middle class, referenced earlier. 
Figure 2: Probability of having purchased certain assets in the previous 12 months for the emerging and established black middle class

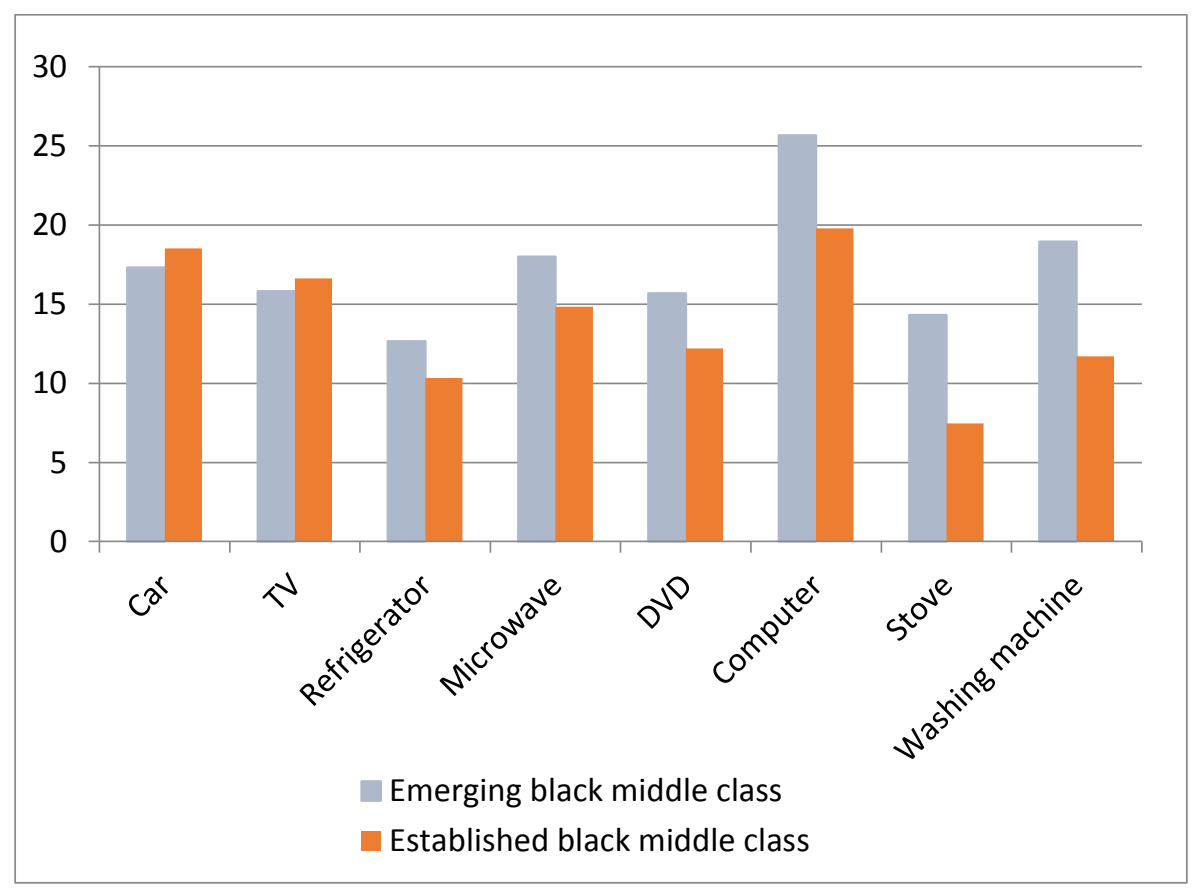

Source: Own calculations from IES2010/11

Typically, tradeoffs are observed between conspicuous consumption and asset expenditure. This does not seem to be the case for the emerging black middle class group, however, and raises the question over how these competing financial demands are being met. If the extension of unsecured - and often unsustainably expensive - credit is a significant enabler, then this is troubling.

\section{Conclusions}

The results of the empirical research reported here are consistent with the hypotheses set out earlier. Conspicuous consumption does appear to be socially contingent, where the reference group is defined as a particular race group. Such conspicuous consumption increases in groups where mean incomes are lower and inequality higher, as was predicted and also found in earlier studies in both South Africa and the USA. Also, in line with hypotheses, a large proportion of the observed high conspicuous consumption levels within the black middle class group can be explained by new or perhaps insecure membership of the group. Finally, the empirical evidence shows that conspicuous consumption is negatively related to asset ownership. As asset ownership rises, thus, it is likely that conspicuous consumption would decrease, perhaps because the need to signal economic status declines commensurately.

Thus the available evidence seems to support an explanation for the pattern of spending amongst black middle class consumers being different from that of their white counterparts largely because of their vulnerability as new entrants to the middle class and also their associated asset deficit. Conspicuous consumption is natural amongst those who are economically more successful than their reference group, and is likely to be a more prominent feature of consumption whilst this higher economic status is still new, and also where such status is still tenuous because of real or perceived income vulnerability. 
If the hypotheses set out here hold, one would expect the more established part of the black middle class to grow over time and to exhibit consumer patterns that would increasingly resemble those of other established members of the middle class. If economic trends continue fuelling growth of the black middle class, social mobility will propel more individuals into the middle class, replenishing the stock of the emerging middle class. Many of these emerging members of the middle class may feel economically vulnerable. Both their new status and vulnerability may increase their desire to strongly signal their economic status through consumption that is conspicuous, while the asset deficits they start out with also would constrain their consumption patterns. However, theory would predict that as the black middle class expands and the link between class and race weakens, there might also be a dilution of the need for signalling wealth.

Given that both this work and that of Kaus et al (2010) are reliant on the IES data, it will be useful to test the robustness of these findings with analysis from other data sources such as the All Media and Products Surveys. 


\section{REFERENCES}

Alexander, P. 2010. Rebellion of the poor: South Africa's service delivery protests - a preliminary analysis. Review of African Political Economy, Vol. 37, No. 123, March 2010, 25-40.

Armer, S. 2013. SA's Black Middle Class Determined To Get Ahead. [Online]. Available: www.supermarket.co.za [9 May].

Bourdieu, P. Distinction. A Social Critique of the Judgement of Taste. London: Routledge, 1984.

Charles, K.K., Hurst, E. and N. Roussanov. 2009. Conspicuous consumption and race. Quarterly Journal of Economics 124(2): 425-467.

http://www.poa.gov.za/Outcomes\%20Publications/Development\%20Indicators\%202012\%20Report. pdf [Date accessed].

Easterly, W. 2001. The middle class consensus and economic development. Journal of Economic Growth, 6: 317-335.

Friedman, M. 1957. A theory of the consumption function. Princeton University Press.

Kaus, W. 2010. Conspicuous consumption and Race: Evidence from South Africa. Papers on Economics and Evolution \#1003.

Krige, D. 2011. 'Debating the black diamond label for South Africa's black middle class'. Paper presented at the annual Anthropology Southern African conference, Stellenbosch University, 3-5 Sept 2011.

Krige, D. 2009. Black diamonds are not forever: Neo-liberal explanations of social change and the South African 'Black Middle Class'. Paper presented at panel 93 "A Continent Transformed?: The Utility of the 'Neo-Liberal' Explanation in African studies' at the 3rd European Conference on African Studies, Leipzig University, Germany, 4-7 June 2009.

Lamont, M., and A. Lareau. Cultural Capital: Allusions, Gaps, and Glissandos in Recent Theoretical Developments. Sociological Theory 6 (1988): 153-168.

Mbeki, T. 1998. Statement of Deputy President Thabo Mbeki at the Opening of the Debate in the National Assembly, on "Reconciliation and Nation Building", National Assembly Cape Town, 29 May 1998.

Mamabolo, K. 2013. 4 Million and rising - The South African black middle class. [Online]. Available: www.fbreporter.com [November 2013].

Modigliani, F. \& Brumberg, R. (1954): 'Utility analysis and the consumption function: An interpretation of cross-section data'. In: Kurihara, K.K (ed.): Post-Keynesian Economics.

Nieftagodien, S. \& Van der Berg, S. 2007. Consumption patterns and the black middle class: The role of assets. Working Paper 02/2007. Stellenbosch University, Department of Economics

Office of the President. 2013. Development Indicators 2012. The Presidency, Pretoria: South Africa. [Online]. Available at:

Schlemmer, L. 2005. Lost in transformation? South Africa's emerging African middle class. CDE Focus No 8. August. Centre for Development and Enterprise: Johannesburg.

Visagie, J. \& D. Posel. 2013. A reconsideration of what and who is middle class in South Africa. Development Southern Africa 30(2): 149-167. 